\title{
Physical Phenomena Occurring in Modeled Cardiac Stent during Decompression Using Numerical Analysis
}

\author{
A. Śliwa AND O. Bialas* \\ Division of Materials Processing Technology and Computer Techniques in Materials Science, \\ Institute of Engineering Materials and Biomaterials, Silesian University of Technology, \\ Konarskiego 18a, 44-100 Gliwice, Poland \\ Doi: $10.12693 /$ APhysPolA.138.133 \\ *e-mail: oktawian.bialas@polsl.pl
}

\begin{abstract}
The work is to establish the crucial physical phenomena responsible for genuine behavior of biomedical devices using numerical analysis in virtual environment. It helps to improve biomechanical functions and allows to predicting possible complications just at the planning stage. In the paper we use physical and mathematical calculations to establish the geometry of a cardiac stent with the help of computer numeric analysis. We determinate the best shape and material for specific life tissue environment conditions and also for the most sustainable parameters for decompression in destination vein area. Our studies include aspects of geometry modelling of a cardio surgery stents with a trial decompression of the model under specific pressure, and comparison of the internal diameter widening for two material: austenitic acid resistant steel AISI 316L - the most common for this purpose, and pure cobalt. Numeric analysis is made due to the model invented in Computer Aided Design program, Solidworks. Physical phenomena registered in the material is caused by specific conditions proportional to the vein area and the pressure occurring in angioplasty balloon. The calculation made with the help of a static analysis in a range of high displacements, with linear-isotropic elastic material model leads to the conclusions.
\end{abstract}

topics: Cardiac stents, stents, decompression, modelling

\section{Introduction}

Currently, many branches of industry and science produce organic and non-organic materials with previously unprecedented properties [1-4]. Many of these materials are used in medicine.

Cardiovascular diseases, being the main global health problem, have become the subject of interest and intensive research of many individuals from different areas of science. Now, we are witnessing an intensive development of interventional cardiology through the introduction of new directions of treatment. One of the most interesting directions, also for bioengineering, is the use of percutaneous intravascular coronary interventions carried out with the implantation of a foreign body-stent [5-7].

Stents are a kind of elastic, most often metal cylindrical scaffolding and their dimensions is of the order of millimetres (see Fig. 1). They are implanted in place of a critical stenosis of a section of the coronary artery in order to support its walls and prevent the occlusion of the vessel lumen. For this reason, the stent is compressed when placed on a "balloon" which, once in the desired section of the artery, is expanded with gas, leading to the opening of the stent and "anchoring" it in a suitable location. There is a wide variety of products on the market that are manufactured from different materials engineering [8-10].

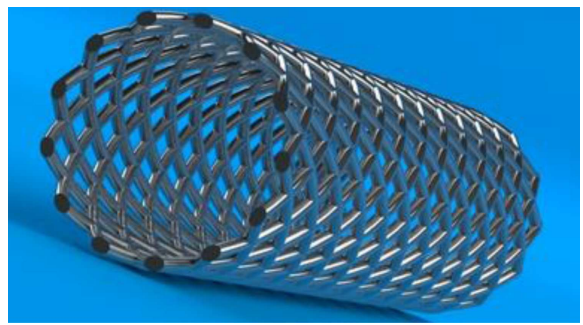

Fig. 1. Stent model made in software from Solidworks.

The Finite Element Method (FEM) is a representative tool used in engineering and scientific computations. It allows to perform computer simulations identifying the effect of various phenomena and processes on the elements made from specific materials subject to the research [11-15].

Various procedures are employed to solve a given issue. Among others: a mesh is applied, boundary conditions are introduced, as a result of which a solution close to the real solution is achieved [16-19].

\section{Material and Method}

In the solid model, we use parameters that, according to our best knowledge, refer to the parameter ranges for which stents are currently produced. 


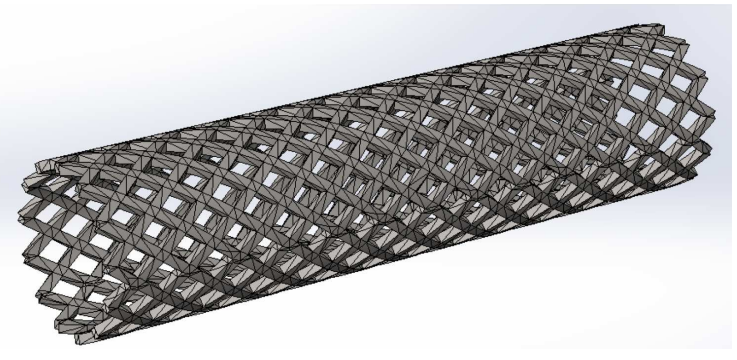

Fig. 2. Numerical Stent model with finite elements division used for analysis.

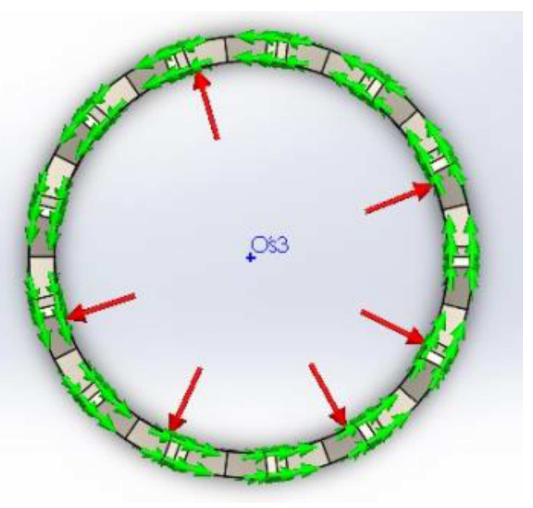

Fig. 3. Estabilished boundary conditions and loads.

Model dimensions.

TABLE I

\begin{tabular}{l|c}
\hline \hline Analysis parameter & Value \\
\hline stent diameter & $3 \mathrm{~mm}$ \\
stent lenght & $13 \mathrm{~mm}$ \\
stent wire thickness & $0.18 \mathrm{~mm}=180 \mu \mathrm{m}$ \\
wires quantity & 13 (occurrences in \\
& a circular formation)
\end{tabular}

Materials comparison used in analysis.

TABLE II

\begin{tabular}{l|c|c}
\hline \hline \multicolumn{1}{c|}{ Material } & AISI 316L & Cobalt \\
\hline coeff. of elasticity $\left[\mathrm{N} / \mathrm{m}^{2}\right]$ & $2 \times 10^{11}$ & $2.11 \times 10^{11}$ \\
Poisson ratio & 0.265 & 0.31 \\
specific mass $\left[\mathrm{kg} / \mathrm{m}^{3}\right]$ & 8027 & 8900 \\
tensile strenght $\left[\mathrm{N} / \mathrm{m}^{2}\right]$ & 485000000 & 235000000 \\
yield strength $\left[\mathrm{N} / \mathrm{m}^{2}\right]$ & 170000000 & -
\end{tabular}

Dimensional parameters are listed in Table I. To simplify the analysis, the wire diameter has been replaced by a square with a side equal to the assumed diameter. The model used for the analysis is presented in Fig. 2. Two materials were selected for the analysis parameters: austenitic acid-resistant steel AISI 316L and pure cobalt. Material characteristics were taken from the library of Solidworks materials, the comparison of which is the most important for the analysis of properties in Table II. For strength analysis, the model was supported by a variable reference geometry that runs with a locked translation in an axial and circular direction. The load in the form of a pressure of $5000 \mathrm{MPa}$ was assumed in the radial direction perpendicular to the axis of the model. The exact visualization of the loads is shown in Fig. 3.

\section{Results}

The distribution of reduced Huber-Mises stress, displacent and deformations in the phase of reaching the maximum level of decompression was showed in Figs. 4-9. The simulation conditions have been established on the basis of parameter optimization and are presented in Table II. On the basis of the displacement distributions it can be concluded that both materials have similar behaviour under the influence of the given conditions of the analysis. It should be noted, however, that the stent model with the assumed material characteristics of 316L steel expands by $0.028 \mathrm{~mm}$ more than the model with the material characteristics of pure cobalt and it has reached $1.183 \mathrm{~mm}$ for AISI 316L model (and $1.155 \mathrm{~mm}$ for Cobalt).

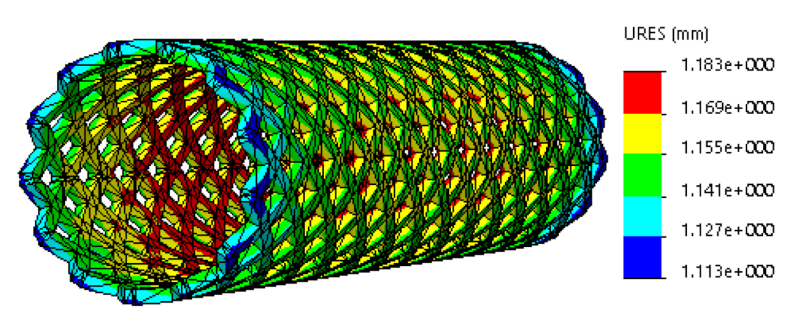

Fig. 4. Displacement results for AISI 316L steel.

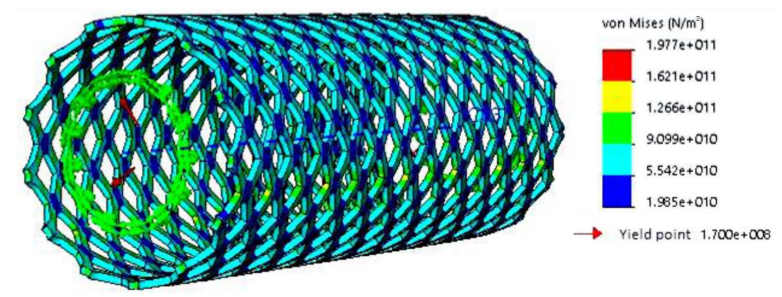

Fig. 5. Huber-Mises Stress distribution results for the AISI 316L steel decompression.

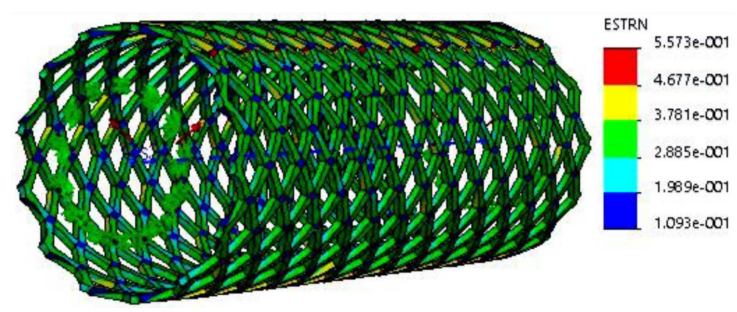

Fig. 6. ESTRN deformation distribution results for the AISI 316L steel decompression. 


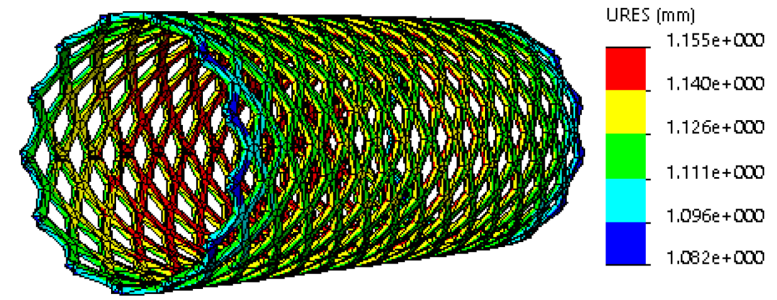

Fig. 7. Displacement results for pure Cobalt.

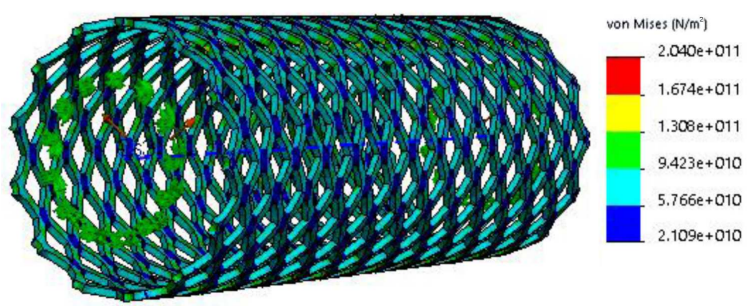

Fig. 8. Huber-Mises Stress distribution results for the pure Cobalt decompression.

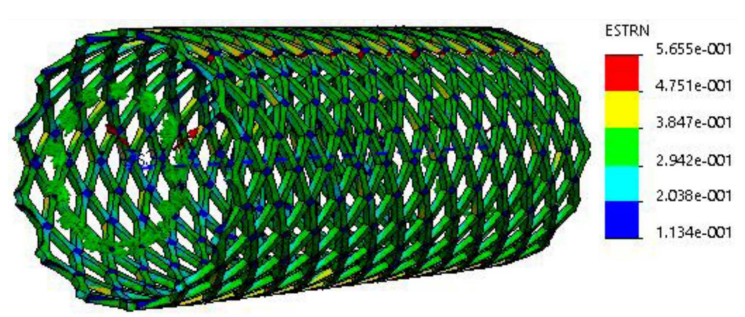

Fig. 9. ESTRN deformation distribution results for pure Cobalt decompression.

The results of the reduced Huber-Mises stresses were not recorded in excess of the yield point for AISI 316L. In terms of deformation, the results showed that the deformation results were achieved at the level of 0,557 ESTRN for the AISI 316L model and 0,565 ESTRN for Cobalt model.

\section{Conclusions}

All analysis is carried out on two materials of the solid stent model under a given load. The results indicate a higher susceptibility to expansion for pure cobalt compared to the most commonly used for stent production AISI 316L steel. The highest expansions according to the analysis are $1.183 \mathrm{~mm}$ for austenitic stainless steel AISI 316L and $1.155 \mathrm{~mm}$ for pure cobalt.

Simulation studies in the assumed conditions of the solid model and the assumed isotropic linearelastic behavior of the material during static linear analysis in the scope of large displacements allowed to state:

- The highest displacements are observed during the expansion of the model made of pure cobalt. It results from a small difference in Young's module of both materials
- Taking into account the nodal connections of the stent grid will result in more accurate and reliable results in the future.

\section{References}

[1] M. Nabiałek, Arch. Metall. Mater. 61, 439 (2016.

[2] B. Jez, M. Nabiałek, K. Jez, Materiale Plastice 56, 1008 (2019).

[3] M.S. Baltatu, C.A. Tugui, M.C. Perju, M. Benchea, M.C. Spataru, A.V. Sandu, P. Vizureanu, Rev. Chim. 70, 1302 (2019).

[4] M. Terrones, A.R. Botello-Méndez, J. Campos-Delgado et al., Nano Today 5(4), 351 (2010).

[5] A. Idziak-Jabłońska, Mechanik, 2015303 (2015).

[6] O. Bialas, J. Żmudzki, J. Achiev. Mater. Manuf. Eng. 92, 1 (2019).

[7] J. Lin, S. Ozan, Y. Li , D. Ping, X. Tong, G. Li, C. Wen, Sci. Rep. 6, 37901 (2016).

[8] J. Marciniak, Stents in Minimally Invasive Surgery, Silesian University of Technology Publisher, Gliwice 2006.

[9] F. Liistro, L. Bolognese, Heart Drug 3, 258 (2003).

[10] O. Schouten, D.Poldermans, Eur. Cardio. Rev. 2, 399 (2006).

[11] A. Śliwa, J. Mikuła, K. Gołombek, W. Kwaśny, D. Pakuła, Arch. Metall. Mater. 61, 1025 (2016).

[12] D. Pakuła , M. Staszuk, K. Gołombek, A. Śliwa, J. Mikuła, Arch. Metall. Mater. 61, 919 (2016).

[13] M. Bonek, A. Śliwa, J. Mikuła, App. Sur. Sci. 388, 174 (2016).

[14] A. Śliwa, W. Kwaśny, W. Sitek, M. Bonek, Arch. Metall. Mater. 61, 481 (2016).

[15] A. Śliwa, W. Kwaśny, M. Sroka, R. Dziwis, Metalurgija 56, 422 (2017).

[16] A. Śliwa, M. Bonek, Metalurgia 65, 223 (2017).

[17] A. Śliwa, M.Sroka, K. Bloch, J.G. Sandu, M.M. Al Bakri Abdullah, A.V. Sandu, Rev. Chim. 69, 324 (2018).

[18] A. Śliwa, M. Sroka, L. Żukowska, K. Bloch, C. Vizureanu, A. Sandu, Rev. Chim. 69, 187 (2018).

[19] A. Śliwa, D. Gros, A.V. Sandu, M. Nabiałek, Rev. Chim. 69, 2813 (2018). 